\title{
Intramyocardial neocavitation: a rare sequela of primary percutaneous coronary intervention
}

\author{
Santosh Kumar Sinha, ${ }^{1}$ Anupam Mahrotra, ${ }^{2}$ Puneet Aggarwal, ${ }^{1}$ Ramesh Thakur ${ }^{1}$
}

${ }^{1}$ Department of Cardiology, LPS Institute of Cardiology, Kanpur, Uttar Pradesh, India

${ }^{2}$ Department of Cardiology, LPS Institute of Cardiology and Cardiac Surgery, Kanpur, Uttar Pradesh, India

\section{Correspondence to} Dr Puneet Aggarwal, puneetaggarwal4u@gmail.com

Accepted 15 November 2018

\section{DESCRIPTION}

A 74-year-old man underwent primary percutaneous coronary intervention (pPCI) for a completely occluded proximal left anterior descending artery. During the procedure, microvascular flow distal to the block could not be established (no-reflow phenomenon) and thus was managed with diltiazem and nicorandil. A follow-up echocardiogram performed on the next day revealed an intraparietal echolucent apicolateral neocavitation corresponding to an intramyocardial haematoma (IMH) along with reduced ejection fraction (EF) of $30 \%$ as compared with $45 \%$ per intervention (figure 1A). At 1 month follow-up, he went into congestive heart failure with a further decline in EF to $25 \%$ (figure $1 \mathrm{~B}$ ). Although the IMH was resolving, left ventricular apex had ballooned out (figure 1C). At 3 months, he was rehospitalised with a storm of ventricular tachycardia and further deterioration in EF with an apical aneurysm (figure 2C), and finally passed away.

Despite the restoration of epicardial patency by pPCI, cardiac systolic function may not recover completely. A restored epicardial blood flow does not necessarily translate into an increased flow at the microvascular level. This impaired microvascular flow, also called as the 'no-reflow', results from microvascular obstruction because of downstream embolisation of microthrombi or atheroma dislodged by manipulations during PCI or from irreversible microvascular injury and subsequent intramyocardial haemorrhage. ${ }^{1}$

IMH is initially contained but tends to dissect through the spiral fibres leading to formation of an intramyocardial neocavity, which produces an echolucent area on echocardiogram limited by the endocardial and epicardial layers. Sometimes, the thrombus inside the neocavity may produce echodense signals (figures $1 \mathrm{~B}, \mathrm{C}$ and 2A). Careful examination of the endocardial and the epicardial layers will rule out other differential diagnoses such as prominent ventricular trabeculations, intracavitary thrombi and pseudoaneurysm. ${ }^{2}$ Treatment of intramyocardial neocavity remains controversial as it may either resolve spontaneously or progress to pseudoaneurysm, rupture or tamponade, which is when surgical intervention is indicated. Echocardiography readily helps in bedside diagnosis and follow-up (figure 2B).
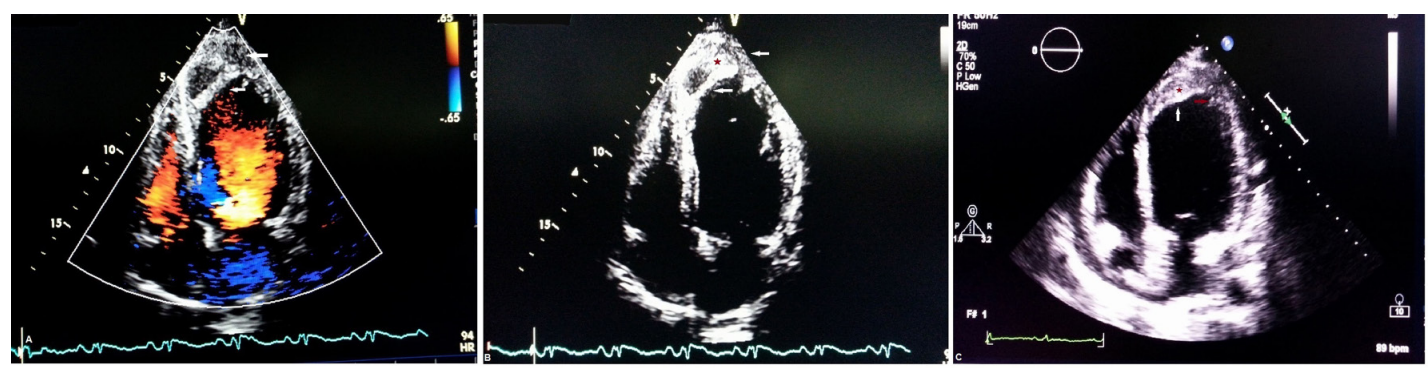

Figure 1 Transthoracic echocardiography (TTE) in apical four-chamber view showing intramyocardial haematoma (IMH) presenting as neocavity at different stages (white arrow—haematoma, red arrow-aneurysm, asterisk signthrombus). (A) Day 1. (B) Two weeks. (C) Fourweeks.

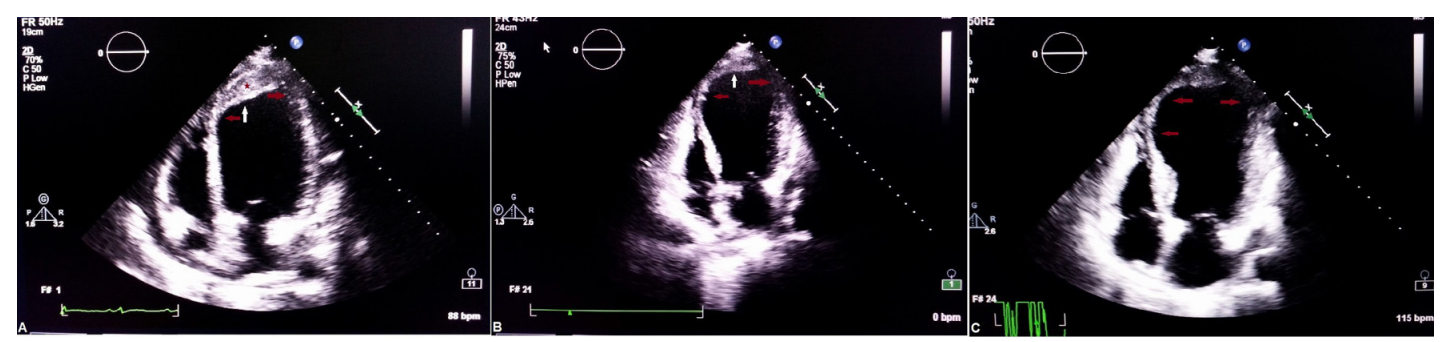

Figure 2 Transthoracic echocardiography (TTE) in apical four-chamber view showing gradual resolution of intramyocardial haematoma (IMH) with ballooning of mid-segment and apical segment of left ventricle at different stages (white arrow—haematoma, red arrow—aneurysm, asterisk sign—-thrombus). (A) Six weeks. (B) Eightweeks. (C) Three months. 


\section{Learning points}

- Intramyocardial haematoma is a rare complication of myocardial reperfusion following primary percutaneous coronary intervention in a totally occluded vessel owing to microvascular dysfunction despite restoring patency of epicardial vessel.

- It is associated with larger infarct, adverse ventricular remodelling, arrhythmias and rarely death.

- It can be easily diagnosed at bedside by echocardiography which also helps in follow-up and therapeutic decisionmaking process.

- It may be prevented by various therapeutic interventions such as gradual instead of abrupt reperfusion, minimum manipulation, preconditioning to prevent endothelial damage and use of pharmacological agents.
Contributors AM: drafting the article or revising it critically for important intellectual content. RT: final approval of the version published. SKS: conception and design, acquisition of data or analysis and interpretation of data. PA: agreement to be accountable for the article and to ensure that all questions regarding the accuracy or integrity of the article are investigated and resolved.

Funding The authors declares that there is no specific grant for this research from any funding agency in the public, commercial or not-for-profit sectors.

Competing interests None declared.

Patient consent Obtained.

Provenance and peer review Not commissioned; externally peer reviewed.

\section{REFERENCES}

1 Betgem RP, de Waard GA, Nijveldt R, et al. Intramyocardial haemorrhage after acute myocardial infarction. Nat Rev Cardiol 2015;12:156-67.

2 Aggeli C, Lampropoulos K, Giannopoulos G, et al. Dissecting intramyocardial haematoma diagnosed by contrast echocardiography. Hellenic J Cardiol 2010;51:166-9.

Copyright 2018 BMJ Publishing Group. All rights reserved. For permission to reuse any of this content visit https://www.bmj.com/company/products-services/rights-and-licensing/permissions/

BMJ Case Report Fellows may re-use this article for personal use and teaching without any further permission.

Become a Fellow of BMJ Case Reports today and you can:

- Submit as many cases as you like

- Enjoy fast sympathetic peer review and rapid publication of accepted articles

- Access all the published articles

- Re-use any of the published material for personal use and teaching without further permission

For information on Institutional Fellowships contact consortiasales@bmjgroup.com

Visit casereports.bmj.com for more articles like this and to become a Fellow 